\title{
The Role of Toll-Like Receptors in the Production of Cytokines by Human Lung Macrophages
}

\author{
Stanislas Grassin-Delyle ${ }^{a, b} \quad$ Charlotte Abrialc Hélène Salvator ${ }^{a, c}$ \\ Marion Brollo $^{c}$ Emmanuel Naline ${ }^{a, c}$ Philippe Devillier ${ }^{a, c}$ \\ a Département des Maladies Respiratoires, Hôpital Foch, Suresnes, France; bINSERM UMR 1173 et Plateforme de \\ spectrométrie de masse MasSpecLab, UFR des Sciences de la Santé Simone Veil, Université Versailles Saint Quentin, \\ Université Paris Saclay, Montigny-le-Bretonneux, France; ' Laboratoire de Pharmacologie UPRES EA220, Université \\ Versailles Saint Quentin, Université Paris Saclay, Hôpital Foch, Suresnes, France
}

\section{Keywords}

Toll-like receptor $\cdot$ Lung macrophage $\cdot$ Polarization .

Cytokine . Chemokine

\begin{abstract}
Background: The Toll-like receptor (TLR) family is involved in the recognition of and response to microbial infections. These receptors are expressed in leukocytes. TLR stimulation induces the production of proinflammatory cytokines and chemokines. Given that human lung macrophages (LMs) constitute the first line of defense against inhaled pathogens, the objective of this study was to investigate the expression and function of TLR subtypes in this cell population. Methods: Human primary LMs were obtained from patients undergoing surgical resection. The RNA and protein expression levels of TLRs, chemokines, and cytokines were assessed after incubation with subtype-selective agonists. Results: In human LMs, the TLR expression level varied from one subtype to another. Stimulation with subtype-selective agonists induced an intense, concentration- and time-dependent increase in the production of chemokines and cytokines. TLR4 stimulation induced the strongest effect, whereas TLR9 stimulation induced a much weaker response. Conclusions: The
\end{abstract}

stimulation of TLRs in human LMs induces intense cytokine and chemokine production, a characteristic of the proinflammatory M1 macrophage phenotype.

(c) 2018 The Author(s)

Published by S. Karger AG, Basel

\section{Introduction}

Macrophages are major players in the homeostatic clearance of apoptotic/damaged cells, the recognition of pathogens, and the induction of an adaptive immune response. These cells reside in all organs but are particularly well-represented in the lungs, where they perform immune surveillance and constitute the body's first line of defense against inhaled pathogens. In addition to their role in innate immunity, macrophages may also promote adaptive immunity through their ability to act as antigenpresenting cells [1]. Macrophages interact with (and then phagocytize) pathogens and damaged cells by binding to a number of receptors expressed at their cell surface (such as scavenger receptors, mannose receptors, and $\beta$-glucan receptors). It is known that the pattern-recognition receptors (PRRs) expressed in macrophages are involved in

\begin{tabular}{ll}
\hline KARGER & $\begin{array}{l}\text { @ } 2018 \text { The Author(s) } \\
\text { Published by S. Karger AG, Basel Oper }\end{array}$ \\
E-Mail karger@karger.com & This article is licensed under the Creative Commons Attribution- \\
www.karger.com/jin & $\begin{array}{l}\text { NonCommercial-NoDerivatives 4.0 International License (CC BY- } \\
\text { NC-ND) (http://www.karger.com/Services/OpenAccessLicense). } \\
\text { Usage and distribution for commercial purposes as well as any dis- } \\
\text { tribution of modified material requires written permission. }\end{array}$
\end{tabular}

Dr. Stanislas Grassin-Delyle

Département des Maladies Respiratoires, Hôpital Foch

11 Rue Guillaume Lenoir

FR-92150 Suresnes (France)

E-Mail s.grassindelyle@hopital-foch.org 
the recognition of either conserved microbial ligands (pathogen-associated molecular patterns [PAMPs]) or endogenous ligands originating from injured cells (damage-associated molecular patterns [DAMPs]) [2]. PRRs encompass the Toll-like receptor (TLR) family, which has 10 members in humans. The TLRs are transmembrane proteins that primarily sense PAMPs (but can also bind to DAMPs) and then induce an immune response. The latter is mainly implemented via the modified expression of transcription factors and inflammatory genes, and the production of mediators (e.g., cytokines). Each of the TLR subtypes has its own specific recognition pattern. TLR1, TLR2, TLR4, TLR5, and TLR6 are located at the cell surface, where they sense external microbial components such as lipopeptides, flagellins, and lipopolysaccharide (LPS, the cell-wall component of gram-negative bacteria). TLR3, TLR7, TLR8, and TLR9 are expressed in intracellular compartments (endosomes) and bind to nucleic acids (such as single- or double-stranded viral RNA and CpG DNA). Some TLRs function as homodimers (TLR3, TLR4, TLR5, and TLR9) or heterodimers (TLR1/2 and TLR2/6), while others are active as monomers (TLR7 and TLR8) [3]. TLR4 (the first subtype to be identified in humans) is the most widely studied, due to its ability to bind LPS, various allergens (e.g., ragweed pollen, house dust extract, and cat dander), and many air pollutants (including particulate matter). It is known that TLR2, TLR4, and TLR9 are expressed in human alveolar macrophages (AMs) at the mRNA level $[4,5]$ and protein level $[6,7]$.

TLR signaling engages an early cytokine response that amplifies the inflammatory response and recruits other cells to combat the invading microorganisms [8]. Macrophages are particularly involved in the production of cytokines; indeed, tumor necrosis factor (TNF)- $\alpha$ and interleukin (IL)-1 $\beta$, IL-6, IL-10, and IL- 12 are released by AMs following the activation of TLR2, TLR4, and TLR9 $[6,7]$. The inhaled microbes recognized by TLR2, TLR4, and TLR9 may cause lung infections and acute exacerbations of chronic obstructive pulmonary disease (COPD) and asthma. Indeed, it was recently reported that bacteria and viruses are associated with, respectively, 55 and $29 \%$ of COPD exacerbations [9]. Viral respiratory tract infections (predominantly due to rhinoviruses) are associated with up to $85 \%$ of asthma exacerbations [10]. Genetic polymorphisms in the TLR genes are also associated with asthma [11, 12]. Cigarette smoke, the most prevalent risk factor for COPD, is also known to alter TLR expression and function in monocyte-derived macrophages [13-15]. Some researchers have therefore suggested that TLRs are potential drug targets for asthma and COPD [16, 17]. Characterization of the response of human lung macrophages (LMs) to TLR stimulation is also of therapeutic interest, since this cell type is a target for TLR-modulating drugs in the preclinical or early clinical development for the treatment of asthma or cystic fibrosis; these drugs include chemically modified mRNAs that modulate TLR expression [18-20] and oligonucleotide TLR9 agonists [21].

It is now acknowledged that macrophages can be polarized into a range of functional phenotypes, depending on various environmental cues. The two ends of the spectrum correspond to proinflammatory M1 macrophages (also referred to as classically activated macrophages) and immunoregulatory M2 macrophages (also referred to as alternatively activated macrophages), thus mirroring the Th1/Th2 dichotomy. M1 macrophages are obtained after stimulation with LPS or by exposure to Th1-cytokines like interferon (IFN)- $\gamma$; the cells are involved in mounting effective responses against microorganisms and tumor cells. M2 macrophages result from stimulation by the Th2 cytokines IL- 4 and IL-13, or by IL-10, immune complexes, or glucocorticoids [22]. They are considered to be "wound-healing" macrophages, as illustrated by their role in the regulation of lung inflammation and tissue remodeling in mouse models of asthma [23, 24]. M1 and M2 macrophages differ markedly with regard to their cytokine production, enzyme content, and surface protein expression. For example, TNF- $\alpha$, CCL3 and CXCL8 are M1 cytokines whereas CCL18 and CCL22 are M2 cytokines [22]. Since some of macrophages' main functions in innate immunity rely on the ability to produce cytokines, we decided to focus on the production of these mediators following the activation of each TLR subtype in human LMs. As recently emphasized [25], there are few literature data on this topic; in particular, there are no comparative data on the stimulation of each TLR subtype in primary cultures of human LMs. Our objective was to map the expression of TLRs in human LMs and characterize the response of cells to selective agonists of each TLR subtype.

\section{Methods}

\section{Reagents}

Penicillin, streptomycin and L-glutamine were purchased from Sigma (St. Louis, MO, USA). RPMI 1640 medium, PBS, FCS, and BSA were obtained from Eurobio Biotechnology (Les Ulis, France). Agonists of TLR1/2 (Pam3CSK4), TLR2 (a heat-killed preparation of Listeria monocytogenes [HKLM]), TLR3 (low- or high-molecular-weight [LMW or HMW] poly[I:C]), TLR4 (LPS from Escherichia coli serotype K12), TLR5 (flagellin from Salmo-
Grassin-Delyle et al. 
nella typhimurium), TLR6/2 (FSL-1), TLR7 (imiquimod), TLR8 (ssRNA40), and TLR9 (ODN2006) were purchased from InvivoGen (San Diego, CA, USA) and resuspended in endotoxin-free water. The maximal concentrations used in this study are listed in online supplemental Table 1 (for all online suppl. material, see www.karger.com/doi/10.1159/000494463). All other chemicals were of analytical grade and were obtained from Merck (Darmstadt, Germany). All cell culture plastics were purchased from CML (Nemours, France).

\section{Patient Population}

The use of resected lung tissue was approved by the regional investigational review board (Comité de Protection des Personnes Ile de France VIII, Boulogne-Billancourt, France), and the patients undergoing surgical lung resection gave their informed consent. Lung tissue was obtained from 19 patients with the following demographic characteristics: a median age of 67 years (interquartile range [IQR] 56-77 years), 11 males and 8 females, a ratio of current smokers/ex-smokers/never-smokers of 12:6:1, median pack-years $n=37$ (IQR 35-60), and \% FEV 1 predicted of 79\% (IQR 67-98\%). Five patients were suffering from COPD (as defined by a postbronchodilator $\mathrm{FEV}_{1} / \mathrm{FVC}$ ratio $<0.7$ ), none had $\mathrm{FEV}_{1}<50 \%$ predicted, and none had undergone chemotherapy or radiotherapy prior to surgical lung resection.

\section{Isolation and Culture of Human LMs}

The procedure for preparation of LMs has been described elsewhere [26-28]. Briefly, peripheral lung tissue obtained from sites distant from the tumor were minced finely and then washed 3 times with RPMI medium. The washings were filtered and centrifuged $(300 \mathrm{~g}, 10 \mathrm{~min})$, and the cell pellet was resuspended in RPMI medium supplemented with $10 \%$ heat-inactivated FCS, 2 mM Lglutamine, $100 \mu \mathrm{g} / \mathrm{mL}$ streptomycin, and $100 \mathrm{U} / \mathrm{mL}$ penicillin. The resuspended cells were then plated at $10^{6}$ viable cells $\bullet \mathrm{mL}^{-1}$. Following incubation for at least $1 \mathrm{~h}$ at $37^{\circ} \mathrm{C}$ in a $5 \% \mathrm{CO}_{2}$ humidified atmosphere, nonadherent cells were removed by gentle washing. Ninety-five percent of the adherent cells were macrophages, and the cell viability exceeded 95\% (in a trypan blue dye exclusion assay).

The next day, adherent LMs were washed with warm RPMI medium lacking FCS, and $1 \mathrm{~mL}$ of fresh medium supplemented with $1 \%$ FCS was then added per well. The cells were treated with the selected TLR1-9 agonists or vehicle. After incubation for between 4 and $48 \mathrm{~h}$, supernatants were collected and stored at $-80^{\circ} \mathrm{C}$ for subsequent cytokine assays. The adherent cells were counted when the supernatant was collected. Adherent cells were also collected in TRIzol reagent for molecular analysis.

\section{Reverse Transcriptase Quantitative Polymerase Chain}

Reaction

After stimulation of the LMs with TLR agonists, the cells were lysed and harvested. Total RNA was extracted with TRIzol ${ }^{\circledR}$ reagent (Life Technologies, Saint Aubin, France). The RNA concentration was determined using a Biowave DNA spectrophotometer (Biochrom, Cambridge, England), and the RNA's purity was evaluated on an Experion microfluidics electrophoresis system using RNA standard sensitivity kits (Bio-Rad, Marnes-la-Coquette, France). Next, after treatment with DNase I (Life Technologies), 1 $\mu \mathrm{g}$ of total RNA was reverse-transcribed using SuperScript ${ }^{\circledR}$ III first-strand SuperMix kit (Life Technologies). A TaqMan ${ }^{\circledR}$ human

The Role of TLRs in the Production of

Cytokines by Human LMs chemokines array and specific TaqMan ${ }^{\circledR}$ arrays based on predesigned reagents (Life Technologies) were used for the analysis of cytokines, chemokines, and TLR transcripts. Real-time quantitative polymerase chain reaction (RT-qPCR) was performed using Gene Expression Master Mix (Life Technologies), with $20 \mathrm{ng}$ of cDNA in a StepOnePlus thermocycler (Life Technologies). Thermal cycling conditions were as follows: initial denaturation at $95^{\circ} \mathrm{C}$ for $10 \mathrm{~min}$, followed by 40 cycles of $95^{\circ} \mathrm{C}$ for $15 \mathrm{~s}$, and $60^{\circ} \mathrm{C}$ for $1 \mathrm{~min}$. Three housekeeping genes (hypoxanthine phosphoribosyltransferase [HPRT1], glyceraldehyde-3-phosphate dehydrogenase $[G A P D H]$, and $\beta$-glucuronidase [GUSB]) were used for the normalization of transcript levels. The expression of 59 cytokine transcripts (22 CC chemokines, 14 CXC chemokines, the $2 \mathrm{C}$ chemokines, the $\mathrm{CX}_{3} \mathrm{C}$ chemokine fractalkine, 13 ILs, 2 IFNs, 2 colony-stimulating factors [CSFs], and 3 TNFs) was assessed in the presence of vehicle or each of the subtype-selective TLR agonists.

\section{Immunoassays}

Cytokines in the LM culture supernatants were measured using an ELISA (Duoset Development System, R\&D Systems, Lille, France). Cytokine concentrations were expressed in ng/ $10^{6} \mathrm{LMs}$. The assays' limits of detection were $4 \mathrm{pg} \bullet \mathrm{mL}^{-1}$ for CCL3, CCL18, CCL22, and IL-1 $\beta ; 8 \mathrm{pg} \bullet \mathrm{mL}^{-1}$ for TNF- $\alpha$, CCL1, and CCL4; 9 $\mathrm{pg} \bullet \mathrm{mL}^{-1}$ for IL-6; and $16 \mathrm{pg} \bullet \mathrm{mL}^{-1}$ for CXCL1 and CXCL8.

\section{Data Expression}

Data were expressed as the mean \pm standard error of the mean (SEM); below, $n$ corresponds to the number of patients from whom LMs were isolated. The RT-qPCR data were expressed as the relative expression $\left(2^{-\Delta \mathrm{Ct}}\right)$ [29]. A gene was considered to be up- or downregulated when its fold-change was $>2$.

\section{Results}

\section{Expression of TLR Transcripts in Human LMs}

LMs were screened for the expression of the genes coding for TLRs. All 10 transcripts were detectable, and the magnitudes of TLR transcript expression were as follows: TLR8 $>$ TLR4 $>$ TLR1 $>$ TLR2 $>$ TLR7 $>$ TLR6 $>$ TLR5 $>$ TLR3 $>$ TLR9 $>$ TLR10 (Fig. 1). There was no correlation between TLR expression on the one hand and sex or FEV on the other; however, TLR2 expression was correlated with age (Spearman's $r=0.7474 ; p=0.0070$ ).

\section{Transcriptional Cytokinome Profiling}

The human LMs were stimulated with the TLR1/2 agonist Pam3CSK4 $\left(1 \mu \mathrm{g} \bullet \mathrm{mL}^{-1}\right)$, the TLR2 agonist HKLM $\left(10^{8}\right.$ cells $\left.\bullet \mathrm{mL}^{-1}\right)$, the TLR3 agonists LMW and HMW poly(I:C) $\left(10 \mu \mathrm{g} \bullet \mathrm{mL}^{-1}\right.$ for both), the TLR4 agonist LPS $\left(10 \mu \mathrm{g} \bullet \mathrm{mL}^{-1}\right)$, the TLR5 agonist flagellin $\left(1 \mu \mathrm{g} \bullet \mathrm{mL}^{-1}\right)$, the TLR6/2 agonist FSL-1 $\left(1 \mu \mathrm{g} \bullet \mathrm{mL}^{-1}\right)$, the TLR7 agonist imiquimod $\left(1 \mu \mathrm{g} \bullet \mathrm{mL}^{-1}\right)$, the TLR8 agonist ssRNA40 $\left(1 \mu \mathrm{g} \bullet \mathrm{mL}^{-1}\right)$, and the TLR9 agonist ODN2006 $(4 \mu \mathrm{M})$. The results are presented in Figure 2. 


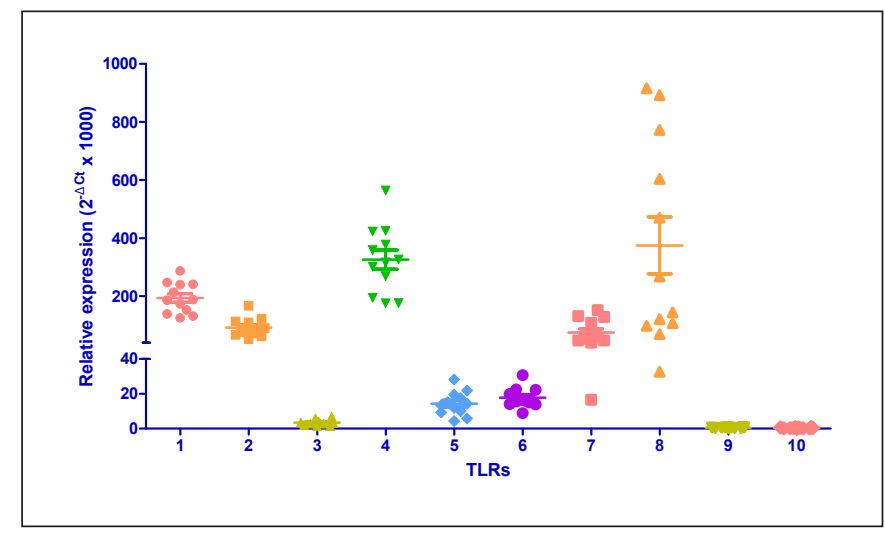

Fig. 1. Transcript expression levels for TLRs in human LMs. Levels of TLR transcripts were determined by RT-qPCR in LMs isolated from 12 patients and normalized against the expression of 3 housekeeping genes, HPRT1, GAPDH, and GUSB.

Of the 22 CC chemokines, 4 (CCL11, CCL16, CCL21, and CCL25) were not expressed in unstimulated LMs, and were not expressed or only weakly expressed following TLR stimulation. Furthermore, 3 CC chemokines (CCL26, CCL27, and CCL28) were weakly expressed in unstimulated LMs and were not upregulated by exposure to the TLR agonists. CCL18 was highly expressed in unstimulated LMs but was not upregulated by the TLR agonists.

The transcripts of all CXCL, C, and CX3C chemokines were found in unstimulated LMs. CXCL4 and CXCL9 were relatively weakly expressed in unstimulated LMs and only weakly upregulated in response to the TLR agonists. Very high expression levels were observed for CXCL5 and CXCL8 in unstimulated LMs. Conversely, CXCL12 transcripts were found in unstimulated cells but could no longer be detected after stimulation with most of the TLR agonists.

Of the 13 ILs, 6 (IL-2, IL-4, IL-5, IL-9, IL-12A, and IL13) were not expressed or only weakly expressed in unstimulated LMs and in response to TLR stimulation. In contrast, IL-12B was weakly expressed in unstimulated LMs but strongly expressed in response to TLR stimulation (except with the TLR3, TLR7, and TLR9 agonists). IL-16 was not upregulated by the TLR agonists. For the growth factors CSF2 and CSF3, transcript levels were higher after exposure to the TLR1, TLR2, TLR4, TLR5, and TLR6 agonists. Transcript levels of both IFN- $\gamma$ and IFN- $\kappa$ were low and only weakly upregulated by TLR agonists.

Although the 3 TNF transcripts were found in unstimulated LMs, only TNF and TNFSF10 were upregulated by exposure to TLR agonists.
The TLR3, TLR4, and TLR5 agonists, i.e., LPS, flagellin, and HMW poly(I:C), respectively, upregulated the greatest number of cytokine transcripts $(32,43$, and 41 genes, respectively). The most intense upregulations were observed for HMW poly(I:C), LPS, and LMW poly(I:C), with $>80$-fold increases for the following genes: CCL4, CCL5, CCL8, CXCL1, CXCL8, CXCL10, CXCL11, IL-1A, $I L-1 B, I L-6, C S F 2, C S F 3, T N F$, and TNFSF10. Imiquimod and ODN2006 induced no or very weak increases in cytokine transcript expression. In contrast, very few genes were downregulated: only 1 was downregulated by Pam3CSK4 (TNFSF10), HKLM (TNFSF10), HMW poly(I:C) (IL-16) and flagellin (CCL28), and only 3 by LPS (IL-16, CCL28, and TNFSF14). The fold-decreases in gene expression were small (range 3.1-6.3).

\section{The Protein Cytokinome: Time Courses and}

Concentration-Response Curves

In view of the transcriptional cytokinome profiling described above, our previous published and unpublished data on LPS [26-28,30], the known involvement of some cytokines in (i) the pathophysiology of COPD and asthma and (ii) the M1/M2 states of macrophage activation, we established concentration-response curves with the different TLR agonists for the production of 10 selected cytokines (Fig. 3). A concentration-dependent response was clearly observed for TNF- $\alpha$, CCL3, CXCL8, IL-1 $\beta$, and IL-6, was less pronounced for CCL1, CCL4, and CXCL1, and was almost nonexistent for CCL18 and CCL22. Among the different TLR agonists, a concentration-response relationship was most often observed for Pam3CSK4, LPS, and FSL-1. Maximum production was usually obtained with the highest concentration of agonist tested. LPS usually induced the greatest increases in cytokine production.

The amounts of cytokine protein released were associated with their transcript level, with the exception of IL$1 \beta$. It is well known that the release of IL- $1 \beta$ is markedly enhanced by extracellular ATP and the toxin nigericin, inducing the caspase-1-dependent release of IL- $1 \beta$ dependent following the formation of the NLRP3 inflammasome [31]. However, an assessment of the regulation of IL- $1 \beta$ release by LMs was beyond the scope of this study. As with the transcript results, the lowest level of cytokine production was observed with imiquimod and ODN2006 (with the exception of TNF- $\alpha$, which was released in large quantities following LM stimulation with ODN2006).

To further investigate the response to agonists, timeresponse curves were obtained for 6 cytokines (Fig. 4).
Grassin-Delyle et al. 


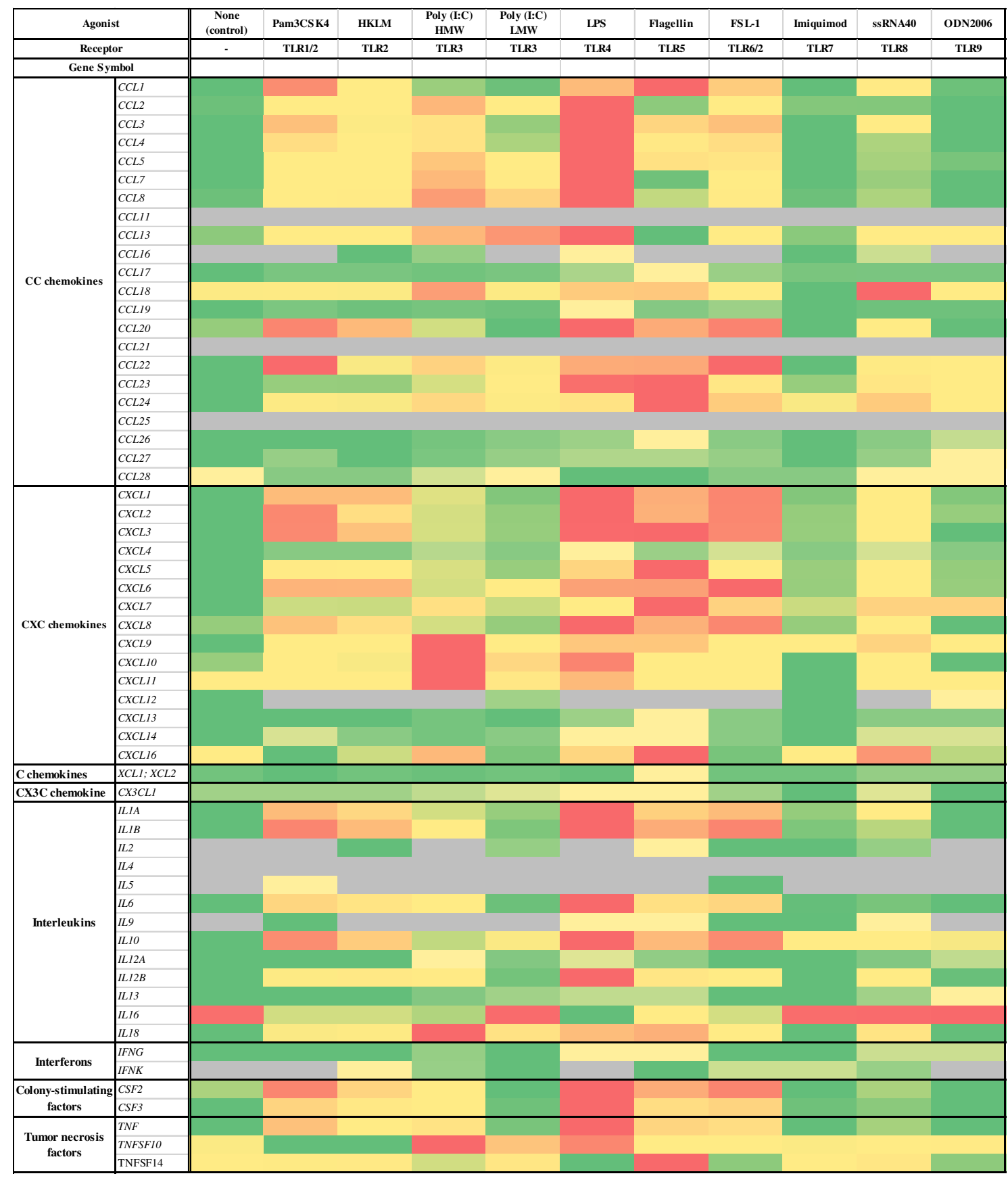

Fig. 2. Expression of cytokine genes in human LMs stimulated (or not [control]) with TLR agonists. Human LMs $(n=3)$ were cultured for $6 \mathrm{~h}$ in the presence or absence of maximal concentrations of the following TLR agonists: the TLR1/2 agonist Pam3CSK4 $\left(1 \mu \mathrm{g} \bullet \mathrm{mL}^{-1}\right)$; the TLR2 agonist HKLM $\left(108\right.$ cells $\left.\bullet \mathrm{mL}^{-1}\right)$; the TLR3 agonists LMW poly(I:C) $\left(10 \mu \mathrm{g} \bullet \mathrm{mL}^{-1}\right)$ and HMW poly(I:C) $\left(10 \mu \mathrm{g} \bullet \mathrm{mL}^{-1}\right)$; the TLR4 agonist LPS $\left(10 \mathrm{~g} \bullet \mathrm{mL}^{-1}\right)$; the TLR5 agonist flagellin $\left(1 \mu \mathrm{g} \bullet \mathrm{mL}^{-1}\right)$; the TLR6/2 agonist FSL-1 $\left(1 \mu \mathrm{g} \bullet \mathrm{mL}^{-1}\right)$; the TLR7 agonist imiquimod $\left(1 \mu \mathrm{g} \bullet \mathrm{mL}^{-1}\right)$; the TLR8 agonist ssRNA40 $\left(1 \mu \mathrm{g} \bullet \mathrm{mL}^{-1}\right)$; and the TLR9 agonist ODN2006 $(4 \mu \mathrm{M})$. Gray, not expressed. 

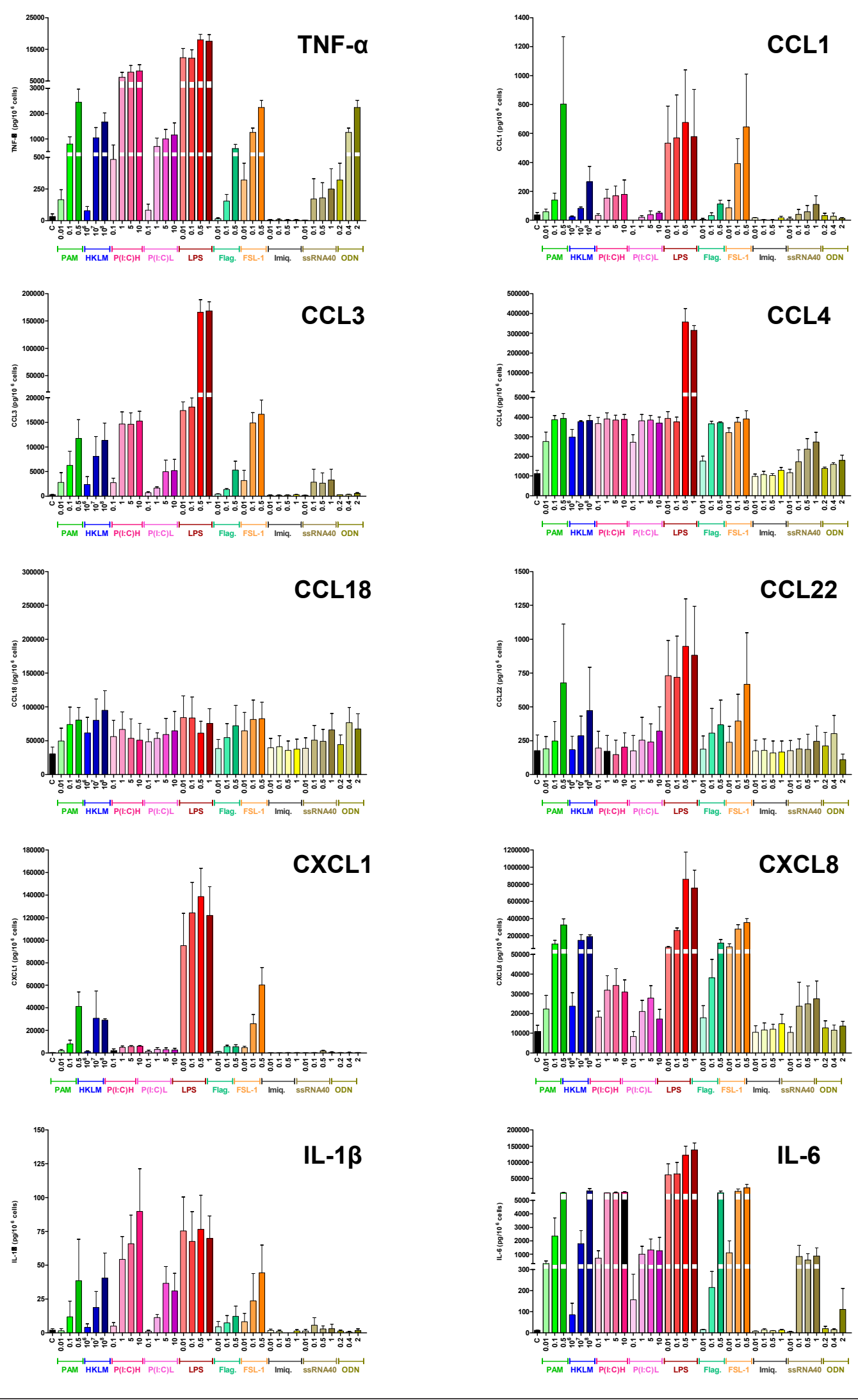

(For legend see next page.) 
For TNF- $\alpha$, CCL3, and CXCL8, an early response (within 4-8 h) was observed for all agonists tested, other than imiquimod and ssRNA40, which had no effect for up to 48 h. For the remaining cytokines, the response time course was intermediate (CXCL1: 8-12 h) or late (CCL18 and CCL22: 24-48 h).

\section{Discussion and Conclusions}

We have described the TLR expression and chemokine production resulting from the stimulation of human LMs with a spectrum of TLR agonists; this enabled us to compare the cell activations triggered by each TLR subtype.

With respect to TLR transcripts, our results are in agreement with those of previous reports in which the highest expression levels were observed for TLR8, TLR1, TLR2, and TLR4 [5]. There was little interpatient variation in the transcript level for all TLRs other than TLR8, which displayed 20 -fold variations from one primary culture to another. In a previous study on mouse AMs obtained by whole lung lavage, the TLR2 and TLR4 transcripts were readily detected but, strikingly, TLR9 transcripts were expressed at negligible levels [32]. In contrast, human AMs obtained by bronchoalveolar lavage from both healthy subjects and patients suffering from sarcoidosis expressed TLR2, TRL6, and TLR9 at similar levels [33]. Our results also indicate that human LMs express TLR9, albeit at a lower level than TLR6, and a much lower level than TLR2.

We also analyzed the transcription of genes coding for cytokines and chemokines after stimulation of the LMs with the different agonists. Overall, all the subtype-selective agonists gave much the same spectrum of transcripts. Only a quantitative analysis might reveal differences between the agonists; the TLR4 agonist appeared to induce the strongest response whereas the TLR7 and TLR9 agonists induced the weakest response. In a mouse model of asthma, an allergic bronchial challenge caused a marked

Fig. 3. Concentration-response curves for the chemokine production induced by subtype-selective TLR agonists. Human LMs were incubated for $6 \mathrm{~h}$ with vehicle or the TLR agonists Pam3CSK4 (TLR1/2 agonist, $0.01-0.5 \mu \mathrm{g} \bullet \mathrm{mL}^{-1}$ ), HKLM (TRL2 agonist, $10^{6}$ $10^{8}$ cells $\bullet \mathrm{mL}^{-1}$ ), LMW poly(I:C) (TLR3 agonist, $0.1-10 \mu \mathrm{g} \bullet \mathrm{mL}^{-1}$ ), HMW poly(I:C) (TLR3 agonist, $0.1-10 \mu \mathrm{g} \bullet \mathrm{mL}^{-1}$ ), LPS (TLR4 agonist, $0.01-1 \mu \mathrm{g} \bullet \mathrm{mL}^{-1}$ ), flagellin (TLR5 agonist, $0.01-0.5 \mu \mathrm{g} \bullet \mathrm{mL}^{-1}$ ), FSL-1 (TLR6/2 agonist, $0.01-0.5 \mu \mathrm{g} \bullet \mathrm{mL}^{-1}$ ), imiquimod (TLR7 agonist, $0.01-1 \mu \mathrm{g} \bullet \mathrm{mL}^{-1}$ ), ssRNA40 (TLR8 agonist, $0.01-1 \mu \mathrm{g} \bullet$ $\mathrm{mL}^{-1}$ ), and ODN2006 (TLR9 agonist, $0.2-2 \mu \mathrm{M}$ ). The values correspond to the mean \pm SEM of 3 or 4 experiments.

The Role of TLRs in the Production of Cytokines by Human LMs increase in inflammatory reactivity to TLR3, TLR4, and TLR7 [34]. In sharp contrast, TLR7 expression and function were found to be markedly reduced in AMs from patients with severe asthma, and this deficiency was linked to an altered microRNA profile [35].

TLR9 mRNA is almost absent in mouse AMs, which are not sensitive to CpG-ODN [32]. The AMs from patients with sarcoidosis were found to express TLR9, and the highest TLR9 expression and the greatest increase in CXCL10 release in response to CpG ODNs was mainly observed in patients with the more acute forms of sarcoidosis, in which macrophages are thought to be classically activated [33]; however, in this particular study, stimulation with $\mathrm{CpG}$ ODNs did not significantly change the release of TNF- $\alpha$, IL-6, IL-12p40, CXCL8, CXCL9, or CXCL11. In our study, the TLR9 agonist clearly increased the production of TNF- $\alpha$ and (to a much lesser degree) IL- 6 but did not cause an increase in the production of IL-1 $\beta$, CCL, and CXC chemokines.

Taken as a whole, our data and the literature data on TLR expression and function in LMs emphasize that the mouse AM is a surrogate cell model that does not adequately recapitulate the biology of human primary LMs.

We next selected a set of M1- and M2-type cytokines involved in COPD or asthma for protein assays [36-40]. TNF- $\alpha$ and chemokines involved in the recruitment of Tlymphocytes (CCL3), monocytes (CCL1), and neutrophils (CXCL1 and CXCL8) were selected as markers of the M1 activation state [37-40], and CCL18 and CCL22 were selected as markers of the M2 activation state [41]. In unstimulated cells, transcript levels and protein levels were closely related. For example, TNF- $\alpha$, CCL1, CCL22, and CXCL1 transcripts and proteins were expressed at low levels in unstimulated LMs whereas CCL18 and CXCL8 displayed high transcript and protein levels. Similarly, most of the TLR agonists induced a concentrationand/or time-dependent increase in chemokine protein expression, which was closely related to the observed increase in the transcript level. However, these relationships were not always observed in LMs stimulated with TLR agonists. On the one hand, the transcripts of TLR1, TLR2, and TLR4 were strongly expressed, and stimulation of these subtypes induced strong cytokine production. On the other hand, TLR8 transcripts were expressed at much the same level as for TLR1, TLR2, and TLR4, although incubation with the agonist ssRNA40 barely produced a cytokine response. This might be related to the physicochemical properties of single-stranded RNA, which might not always be able to gain access to intracellular TLR8. In contrast, ODN2006 (the agonist of TLR9,

Innate Immun 2020;12:63-73 


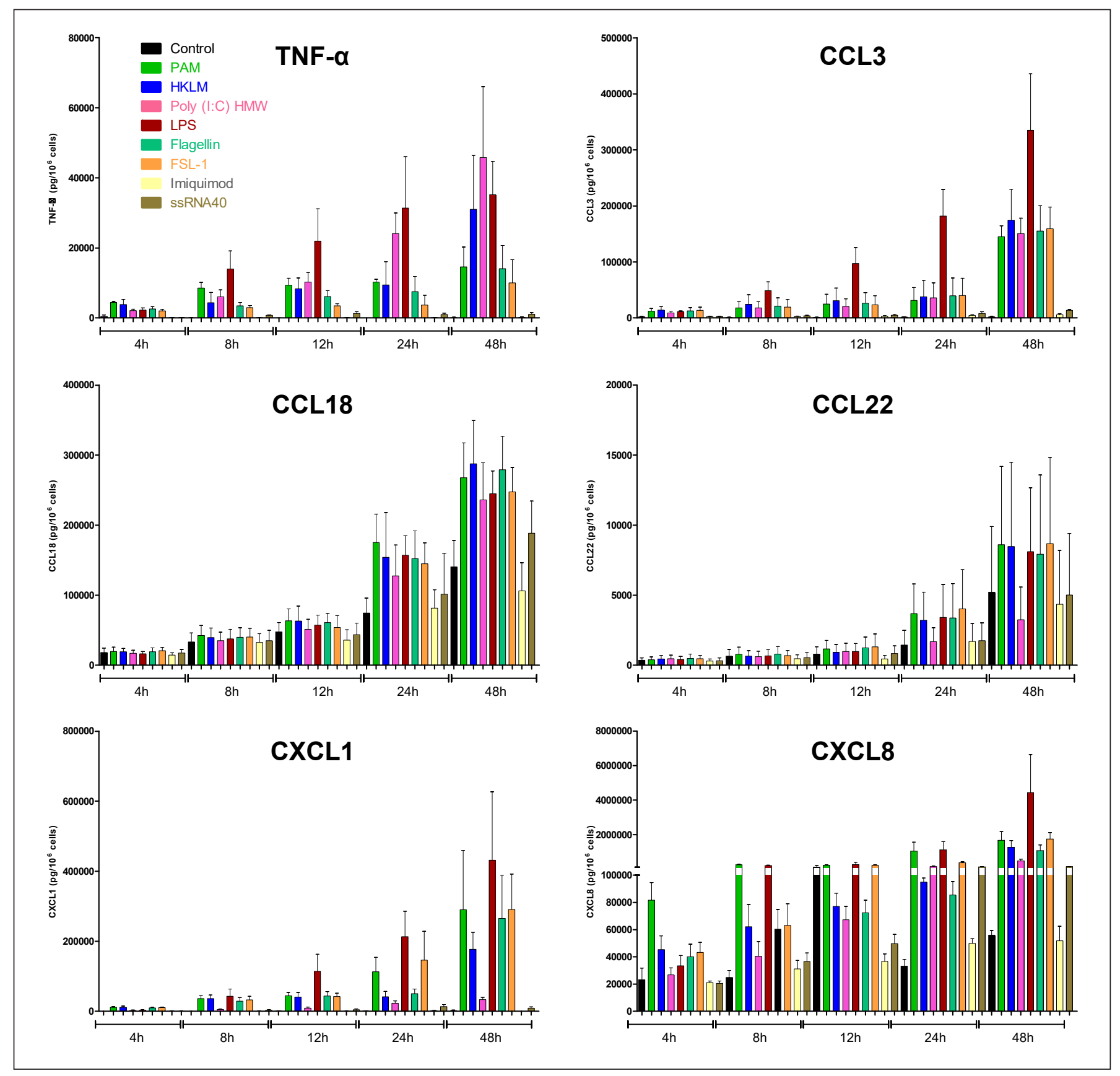

Fig.4. Time-response curves for the chemokine production induced by subtype-selective TLR agonists. Human LMs were incubated for 4-48 h with vehicle or the TLR agonists Pam3CSK4 (TLR1/2 agonist, $1 \mu \mathrm{g} \bullet \mathrm{mL}^{-1}$ ), HKLM (TRL2 agonist, $10^{8}$ cells $\bullet \mathrm{mL}^{-1}$ ), LMW poly(I:C) (TLR3 agonist, $10 \mu \mathrm{g} \bullet \mathrm{mL}^{-1}$ ), HMW poly(I:C) (TLR3 ago-

nist, $10 \mu \mathrm{g} \bullet \mathrm{mL}^{-1}$ ), LPS (TLR4 agonist, $1 \mu \mathrm{g} \bullet \mathrm{mL}^{-1}$ ), flagellin (TLR5 agonist, $1 \mu \mathrm{g} \bullet \mathrm{mL}^{-1}$ ), FSL-1 (TLR6/2 agonist, $1 \mu \mathrm{g} \bullet \mathrm{mL}^{-1}$ ), imiquimod (TLR7 agonist, $1 \mu \mathrm{g} \bullet \mathrm{mL}^{-1}$ ), ssRNA40 (TLR8 agonist, $1 \mu \mathrm{g} \bullet$ $\mathrm{mL}^{-1}$ ), and ODN2006 (TLR9 agonist, $4 \mu \mathrm{M}$ ). The values correspond to the mean \pm SEM of 3 experiments.

which was very weakly expressed at the mRNA level) induced the intense production of TNF- $\alpha$ but did not induce production of the other cytokines tested. The release of cytokines considered to be specific for the M2 macro-

phage polarization state (e.g., CCL18 and CCL26) was not stimulated by the TLR agonists, whereas the release of other cytokines (e.g., CCL13 and 22) increased moderately (3- to 8-fold). Levels of CCL17 (also considered to 
be an M2 cytokine) increased 10- and 21-fold after LM stimulation with LPS and flagellin, respectively.

Some of the chemokines that were not stimulated at the mRNA level (e.g., CCL18) were also not stimulated at the protein level in our study of the concentration-response relationship. This is probably due to the effect of time. In fact, CCL18 is often described as an M2-type cytokine that is released in the late phase of the inflammatory response (i.e., to end inflammation and induce immunoregulation). Hence, the increase in the CCL18 protein level was observed at later time points (from $24 \mathrm{~h}$ onwards), and so one would expect transcript levels to increase too during this period. Similar conclusions can be drawn for CCL22, for exactly the same reasons. In contrast, the M1-type chemokines assessed in this study had an early time course of expression at both the transcript and protein levels, as is typically observed. This finding is in agreement with the commonly described switch in macrophage polarization, where M1 macrophages actively participate in the onset of the inflammatory reaction and then switch to the M2 phenotype involved in the healing and repair processes [42].

When analyzing the pattern of cytokines and chemokines produced here in response to the TLR agonists, we noted that very similar transcript and protein profiles were produced in response to all the agonists. Even though various agonists from different microbial sources stimulated different TLRs, the subsequent innate immune responses were similar in terms of the nature of the chemokines produced, although the relative intensity of expression could differ. Most of the chemokines produced in response to TLR stimulation are involved in the onset and then maintenance of the inflammatory response via the recruitment of several cell types. In the this study, the target cell types are relevant to lung diseases. For example, we observed changes in the production of the chemokines involved in the recruitment of T-lymphocytes (CCL3, CCL4, CXCL9, and CXCL10), monocytes (CCL2), and neutrophils (CXCL1, CXCL5, and CXCL8); infiltration of the lungs by these inflammatory cell types is a hallmark of COPD [36-40].

The strengths of our study include a comparison of the effects of TLR activation on a broad spectrum of cytokines, in a series of experiments on paired preparations. The potential limitations relate to the use of LMs harvested from resected lung tissues and from a mixture of current smokers and ex-smokers. The cell isolation procedure using minced lung tissues had the enormous advantage of providing the large number of cells required for the paired series of experiments that we conducted; this

The Role of TLRs in the Production of Cytokines by Human LMs would hardly be possible with macrophages obtained from bronchoalveolar lavage. However, our preparations might have contained a small proportion of interstitial/ tissue resident macrophages, along with the great majority of AMs. A recent study with a pig model demonstrated that AMs and dendritic cells are similar to their interstitial counterparts [43]. Hoppstädter et al. [5] did not find any differences between interstitial and alveolar populations with respect to TLR expression levels or phagocytotic function but did suggest that the LPS-induced release of IL-6, IL-1 $\beta$, or IL-12 differed between the 2 macrophage subtypes when stimulated after several days in culture. Once extracted from their native microenvironment and cultured ex vivo, macrophages undergo rapid morphological and phenotypical changes; the results of studies of ex vivo-cultured interstitial macrophages must therefore be interpreted with caution [44]. In the lung, exposure to TLR agonists is not restricted to the alveolar compartment; hence, the use of freshly isolated human LMs mainly from the alveolar spaces, but perhaps also from the lung tissue, might usefully reflect the clinical response more closely.

Most of the lung tissue used in this study came from current smokers and ex-smokers because surgical lung resection was performed for cancer. The impact of smoking status and COPD on TLR4-induced (but also TLR2induced) cytokine release by LMs varies markedly from one study to another, and as a function of the cytokines measured and the TLR-agonists used. Some researchers have reported that LPS-stimulated cytokine production from AMs is higher in COPD patients and smokers than in healthy nonsmokers [45]. However, there were no significant differences in cytokine secretion between the current smokers with COPD and nonsmokers with COPD. In contrast, other studies have shown that (i) smoking reduces cytokine production by AMs upon stimulation with TLR2 and TLR4 agonists but not with a TLR3 agonist [46] or (ii) current smoking status had no effect, since the dose-response curves for the LPS-stimulated cytokines were similar in current smokers and exsmokers [47-49].

We studied all the TLR agonists in the same series of paired experiments, and so differences in cytokine production are therefore related to the TLR agonists' effects and not to differences in the characteristics of the patients from which the LMs were derived.

In conclusion, we described the spectrum and time course of chemokine and cytokine production by human LMs in response to stimulation by subtype-selective TLR agonists. Although LPS is considered the archetypal li- 
gand for the induction of M1 macrophage polarization, our results suggest that almost all of the other TLR subtype agonists can induce M1 polarization in human LMs. Our results further characterized the M1 phenotype in human LMs and validated the experimental use of TLR agonists in general (rather than just LPS) as M1-polarizing agents.

\section{Acknowledgments}

The authors thank Dr. David Fraser (Biotech Communication, Ploudalmezeau, France) for copy-editing the manuscript.

\section{Statement of Ethics}

The use of resected lung tissue was approved by the regional investigational review board (Comité de Protection des Personnes Ile de France VIII, Boulogne-Billancourt, France), and the patients undergoing surgical lung resection gave their informed consent.

\section{Disclosure Statement}

The authors declare no conflict of interest.

\section{References}

1 Davies LC, Jenkins SJ, Allen JE, Taylor PR. Tissue-resident macrophages. Nat Immunol. 2013 Oct;14(10):986-95.

2 Akira S, Uematsu S, Takeuchi O. Pathogen recognition and innate immunity. Cell. 2006 Feb;124(4):783-801.

3 Bauer RN, Diaz-Sanchez D, Jaspers I. Effects of air pollutants on innate immunity: the role of Toll-like receptors and nucleotide-binding oligomerization domain-like receptors. J Allergy Clin Immunol. 2012 Jan;129(1):14-24.

4 Maris NA, Dessing MC, de Vos AF, Bresser P, van der Zee JS, Jansen HM, et al. Toll-like receptor mRNA levels in alveolar macrophages after inhalation of endotoxin. Eur Respir J. 2006 Sep;28(3):622-6.

5 Hoppstädter J, Diesel B, Zarbock R, Breinig T, Monz D, Koch M, et al. Differential cell reaction upon Toll-like receptor 4 and 9 activation in human alveolar and lung interstitial macrophages. Respir Res. 2010 Sep;11(1):124.

6 Juarez E, Nuñez C, Sada E, Ellner JJ, Schwander SK, Torres M. Differential expression of Toll-like receptors on human alveolar macrophages and autologous peripheral monocytes. Respir Res. 2010 Jan;11(1):2.

7 Hoogerwerf JJ, de Vos AF, van't Veer C, Bresser P, de Boer A, Tanck MW, et al. Priming of alveolar macrophages upon instillation of lipopolysaccharide in the human lung. Am J Respir Cell Mol Biol. 2010 Mar;42(3):34956.

8 Strieter RM, Belperio JA, Keane MP. Host innate defenses in the lung: the role of cytokines. Curr Opin Infect Dis. 2003 Jun;16(3): 193-8.

9 Bafadhel M, McKenna S, Terry S, Mistry V, Reid C, Haldar P, et al. Acute exacerbations of chronic obstructive pulmonary disease: identification of biologic clusters and their biomarkers. Am J Respir Crit Care Med. 2011 Sep;184(6):662-71.

10 Busse WW, Lemanske RF Jr, Gern JE. Role of viral respiratory infections in asthma and asthma exacerbations. Lancet. 2010 Sep; 376(9743):826-34.
11 Eder W, Klimecki W, Yu L, von Mutius E, Riedler J, Braun-Fahrländer C, et al.; ALEX Study Team. Toll-like receptor 2 as a major gene for asthma in children of European farmers. J Allergy Clin Immunol. 2004 Mar; 113(3):482-8.

12 Kormann MS, Depner M, Hartl D, Klopp N, Illig T, Adamski J, et al. Toll-like receptor heterodimer variants protect from childhood asthma. J Allergy Clin Immunol. 2008;122: 86-92.

13 Sarir H, Mortaz E, Karimi K, Kraneveld AD, Rahman I, Caldenhoven E, et al. Cigarette smoke regulates the expression of TLR4 and IL- 8 production by human macrophages. J Inflamm (Lond). 2009 May;6(1):12.

14 Karimi K, Sarir H, Mortaz E, Smit JJ, Hosseini $\mathrm{H}$, De Kimpe SJ, et al. Toll-like receptor-4 mediates cigarette smoke-induced cytokine production by human macrophages. Respir Res. 2006 Apr;7(1):66.

15 Koarai A, Yanagisawa S, Sugiura H, Ichikawa T, Akamatsu K, Hirano T, et al. Cigarette smoke augments the expression and responses of toll-like receptor 3 in human macrophages. Respirology. 2012 Aug;17(6):101825.

16 Hansel TT, Barnes PJ. New drugs for exacerbations of chronic obstructive pulmonary disease. Lancet. 2009 Aug;374(9691):744-55.

17 Paul-Clark MJ, George PM, Gatheral T, Parzych K, Wright WR, Crawford D, et al. Pharmacology and therapeutic potential of pattern recognition receptors. Pharmacol Ther. 2012 Aug;135(2):200-15.

18 Zeyer F, Mothes B, Will C, Carevic M, Rottenberger J, Nürnberg B, et al. mRNA-mediated gene supplementation of Toll-like receptors as treatment strategy for asthma in vivo. PLoS One. 2016 Apr;11(4):e0154001.

19 Robinson E, MacDonald KD, Slaughter K, McKinney M, Patel S, Sun C, et al. Lipid nanoparticle-delivered chemically modified mRNA restores chloride secretion in cystic fibrosis. Mol Ther. 2018 Aug;26(8):2034-46.
20 Antony JS, Dewerth A, Haque A, Handgretinger R, Kormann MS. Modified mRNA as a new therapeutic option for pediatric respiratory diseases and hemoglobinopathies. Mol Cell Pediatr. 2015 Dec;2(1):11.

21 Jackson S, Candia AF, Delaney S, Floettmann S, Wong C, Campbell JD, et al. First-in-human study with the inhaled TLR9 oligonucleotide agonist AZD1419 results in interferon responses in the lung, and is safe and welltolerated. Clin Pharmacol Ther. 2018 Aug; 104(2):335-45.

22 Mantovani A, Sica A, Sozzani S, Allavena P, Vecchi A, Locati M. The chemokine system in diverse forms of macrophage activation and polarization. Trends Immunol. 2004 Dec; 25(12):677-86

23 Byers DE, Holtzman MJ. Alternatively activated macrophages and airway disease. Chest. 2011 Sep;140(3):768-74.

24 Dasgupta P, Keegan AD. Contribution of alternatively activated macrophages to allergic lung inflammation: a tale of mice and men. J Innate Immun. 2012;4(5-6):478-88.

25 Baral P, Batra S, Zemans RL, Downey GP, Jeyaseelan S. Divergent functions of Toll-like receptors during bacterial lung infections. Am J Respir Crit Care Med. 2014 Oct;190(7):722-32.

26 Buenestado A, Grassin Delyle S, Arnould I, Besnard F, Naline E, Blouquit-Laye S, et al. The role of adenosine receptors in regulating production of tumour necrosis factor-alpha and chemokines by human lung macrophages. $\mathrm{Br} \mathrm{J}$ Pharmacol. 2010 Mar;159(6):1304-11.

27 Buenestado A, Grassin-Delyle S, Guitard F, Naline E, Faisy C, Israël-Biet D, et al. Roflumilast inhibits the release of chemokines and TNF- $\alpha$ from human lung macrophages stimulated with lipopolysaccharide. Br J Pharmacol. 2012 Mar;165(6):1877-90.

28 Victoni T, Salvator H, Abrial C, Brollo M, Porto LC, Lagente V, et al. Human lung and monocyte-derived macrophages differ with regard to the effects of $\beta 2$-adrenoceptor agonists on cytokine release. Respir Res. 2017 Jun;18(1):126. 
29 Livak KJ, Schmittgen TD. Analysis of relative gene expression data using real-time quantitative PCR and the 2(-Delta Delta C(T)) Method. Methods. 2001 Dec;25(4):402-8.

30 Abrial C, Grassin-Delyle S, Salvator H, Brollo M, Naline E, Devillier P. 15-Lipoxygenases regulate the production of chemokines in human lung macrophages. Br J Pharmacol. 2015 Sep;172(17):4319-30.

31 Lopez-Castejon G, Brough D. Understanding the mechanism of IL-1 $\beta$ secretion. Cytokine Growth Factor Rev. 2011 Aug;22(4):189-95.

32 Suzuki K, Suda T, Naito T, Ide K, Chida K, Nakamura H. Impaired toll-like receptor 9 expression in alveolar macrophages with no sensitivity to CpG DNA. Am J Respir Crit Care Med. 2005 Apr;171(7):707-13.

33 Schnerch J, Prasse A, Vlachakis D, Schuchardt KL, Pechkovsky DV, Goldmann T, et al. Functional Toll-like receptor 9 expression and CXCR3 ligand release in pulmonary sarcoidosis. Am J Respir Cell Mol Biol. 2016 Nov; 55(5):749-57.

34 Naessens T, Vander Beken S, Bogaert P, Van Rooijen N, Lienenklaus S, Weiss S, et al. Innate imprinting of murine resident alveolar macrophages by allergic bronchial inflammation causes a switch from hypoinflammatory to hyperinflammatory reactivity. Am J Pathol. 2012 Jul;181(1):174-84.

35 Rupani H, Martinez-Nunez RT, Dennison P, Lau LC, Jayasekera N, Havelock T, et al. Tolllike receptor 7 is reduced in severe asthma and linked to an altered microRNA profile. Am J Respir Crit Care Med. 2016 Jul;194(1):26-37.
36 Barnes PJ. The cytokine network in chronic obstructive pulmonary disease. Am J Respir Cell Mol Biol. 2009 Dec;41(6):631-8.

37 Capelli A, Di Stefano A, Gnemmi I, Balbo P, Cerutti CG, Balbi B, et al. Increased MCP-1 and MIP-1beta in bronchoalveolar lavage fluid of chronic bronchitics. Eur Respir J. 1999 Jul;14(1):160-5.

38 Costa C, Rufino R, Traves SL, Lapa E Silva JR, Barnes PJ, Donnelly LE. CXCR3 and CCR5 chemokines in induced sputum from patients with COPD. Chest. 2008 Jan;133(1):26-33.

39 Keatings VM, Collins PD, Scott DM, Barnes PJ. Differences in interleukin-8 and tumor necrosis factor-alpha in induced sputum from patients with chronic obstructive pulmonary disease or asthma. Am J Respir Crit Care Med. 1996 Feb;153(2):530-4.

40 Traves SL, Culpitt SV, Russell RE, Barnes PJ, Donnelly LE. Increased levels of the chemokines GROalpha and MCP-1 in sputum samples from patients with COPD. Thorax. 2002 Jul;57(7):590-5.

41 Kim EY, Battaile JT, Patel AC, You Y, Agapov E, Grayson $\mathrm{MH}$, et al. Persistent activation of an innate immune response translates respiratory viral infection into chronic lung disease. Nat Med. 2008 Jun;14(6):633-40.

42 Stout RD, Suttles J. Functional plasticity of macrophages: reversible adaptation to changing microenvironments. J Leukoc Biol. 2004 Sep;76(3):509-13.
43 Maisonnasse P, Bordet E, Bouguyon E, Bertho N. Broncho alveolar dendritic cells and macrophages are highly similar to their interstitial counterparts. PLoS One. 2016 Dec; 11(12): 0167315

44 Schyns J, Bureau F, Marichal T. Lung interstitial macrophages: past, present, and future. J Immunol Res. 2018 Apr;2018:5160794.

45 Hodge S, Matthews G, Mukaro V, Ahern J, Shivam A, Hodge G, et al. Cigarette smokeinduced changes to alveolar macrophage phenotype and function are improved by treatment with procysteine. Am J Respir Cell Mol Biol. 2011 May;44(5):673-81.

46 Chen H, Cowan MJ, Hasday JD, Vogel SN, Medvedev AE. Tobacco smoking inhibits expression of proinflammatory cytokines and activation of IL-1R-associated kinase, p38, and NF-kappaB in alveolar macrophages stimulated with TLR2 and TLR4 agonists. J Immunol. 2007 Nov;179(9):6097-106.

47 Armstrong J, Harbron C, Lea S, Booth G, Cadden P, Wreggett KA, et al. Synergistic effects of p38 mitogen-activated protein kinase inhibition with a corticosteroid in alveolar macrophages from patients with chronic obstructive pulmonary disease. J Pharmacol Exp Ther. 2011 Sep;338(3):732-40.

48 Armstrong J, Sargent C, Singh D. Glucocorticoid sensitivity of lipopolysaccharide-stimulated chronic obstructive pulmonary disease alveolar macrophages. Clin Exp Immunol. 2009 Oct;158(1):74-83.

49 Higham A, Booth G, Lea S, Southworth T, Plumb J, Singh D. The effects of corticosteroids on COPD lung macrophages: a pooled analysis. Respir Res. 2015 Aug;16(1):98.
The Role of TLRs in the Production of Cytokines by Human LMs
J Innate Immun 2020;12:63-73

DOI: $10.1159 / 000494463$ 